\title{
Novel ratiometric fluorescent probe based on internal reference and its detection of hydrazine
}

\author{
Xiaohong Cheng ${ }^{1 *}$, Shuang $\mathrm{Li}^{2}$, Mengyun Gong ${ }^{1}$, Song Wang ${ }^{1}$, Wangnan $\mathrm{Li}^{1}$ \\ $\left({ }^{1}\right.$ Hubei Key Laboratory of Low Dimensional Optoelectronic Materials and Devices, Hubei \\ University of Arts and Science, Xiangyang 441053, Hubei Province, P. R. China; ${ }^{2}$ Hubei Institute \\ of Aerospace Chemical Technology, Xiangyang 441003, Hubei Province, P. R. China)
}

\begin{abstract}
In this work, dual-emissive ratiometric fluorescent system was constructed by the introduction of an ideal internal reference. By virtue of its unique alkalinity, $\mathrm{N}_{2} \mathrm{H}_{4}$ could undergo a hydrazinolysis reaction with the ester group of $\mathbf{F 1}$, inducing remarkable fluorescence enhancement while the blue fluorescence of the internal reference DPA remained constant. Consequently, the fluorescence intensity ratios $\left(\mathrm{I}_{540} / \mathrm{I}_{440}\right)$ were proportional to the concentrations of $\mathrm{N}_{2} \mathrm{H}_{4}$, which was beneficial for the exactly quantitative detection. The skillful strategy granted the sensing system advantages such as relative good solubility in aqueous media, easy-to-design, simple synthesis, large emission shift, good ratiometric response, as well as the successful application in real water samples and cell imaging.
\end{abstract}

Keywords: Fluorescent probe; Hydrazine; Ratiometric response; Practical detection; Cell imaging

\section{Introduction}

Currently, the development of organic fluorophores-based probes for toxic agents such as hydrazine $\left(\mathrm{N}_{2} \mathrm{H}_{4}\right)$ [1-11], has been a subject of intense research interest. On the one hand, $\mathrm{N}_{2} \mathrm{H}_{4}$ plays an important role in the chemical, pharmaceutical and agricultural industries involving catalysts, photography chemicals, pesticides, various dyes, pharmaceutical intermediates and so on [12-15]. Nevertheless, on the other, $\mathrm{N}_{2} \mathrm{H}_{4}$ is recognized as a hazardous substance to biological processes and human health. It damages DNA by excess production of defective proteins, and gets metabolized into toxic radical species [16]. Hydrazine is also a neurotoxin and has severe mutagenic effects causing severe damage to the liver, lungs, kidneys and human central nervous system [17]. Thus, the highest permissible of $\mathrm{N}_{2} \mathrm{H}_{4}$ concentration is limited to $0.312 \mu \mathrm{mol} / \mathrm{L}$ in drinking water according to the U.S. environmental protection agency (EPA) [18]. Therefore, easy and reliable methods are in great demand for hydrazine detection in the environmental and biological systems.

In this regard, fluorescent technique for $\mathrm{N}_{2} \mathrm{H}_{4}$ detection have been studied actively due to their appealing merits such as high sensitivity, specificity, and rapid response, enabling successful application both in vitro assays and in vivo imaging studies [19-25]. Especially, ratiometric method is

\footnotetext{
* Corresponding author: Xiaohong Cheng. Email: chengxiaohong0807@126.com; tel: +86-07103590061.
} 
becoming more promising as it can enable the measurement of optical intensities at two different wavelengths, providing a built-in correction for environmental effects and increasing the dynamic range of measurement. Compared with the intensity-based ones, this type of probes can acquire accurate results and be more beneficial to quantitative measurements [26-30]. For practical use in ratiometric measurement, an ideal fluorescent probe should exhibit a large emission wavelength shift (>80 nm). Generally, ratiometric probes can be designed through two mechanisms [31-33] including fluorescence resonance energy transfer (FRET) and intramolecular charge transfer (ICT). However, both methods consist complicated chemical structure design and synthetic procedures. As a result, it is urgent to explore a facile fabrication strategy of simple but reliable ratiometric sensing system for $\mathrm{N}_{2} \mathrm{H}_{4}$.

With these considerations in mind, herein, we developed a dual-emissive ratiometric fluorescent system for $\mathrm{N}_{2} \mathrm{H}_{4}$ detection. Firstly, we designed compound F1 (Scheme 1), which was composed of a fluorescein moiety and acetate group. The fluorescein moiety was selected to act as the fluorophore with relatively good solubility in water media and the acetate group was chosen as a putative $\mathrm{N}_{2} \mathrm{H}_{4}$-dependent reactive subunit. Taking advantage of the unique alkalinity of $\mathrm{N}_{2} \mathrm{H}_{4}$, the $\mathrm{N}_{2} \mathrm{H}_{4}$-promoted hydrolysis reaction would trigger the cleavage of the C-O bond in compound F1, resulting in the photoswitch of the non-fluorescent deconjugated form to the strongly fluorescent conjugated one (F2). As a result, the electronic structure and optical properties would change, and F1 could act as a $\mathrm{N}_{2} \mathrm{H}_{4}$-specifity probe via a turn-on approach. As illustrated in Scheme 1, the emission spectra of $\mathbf{F 1}$ first enhanced with the addition of $\mathrm{N}_{2} \mathrm{H}_{4}$. Then, 9,10-Diphenylanthracene (DPA) was introduced as the internal reference to construct an ideal ratiometric sensing system. As to the F1-DPA system, the blue emission of DPA was almost unchanged while the green emission of F1 increasing with the addition of $\mathrm{N}_{2} \mathrm{H}_{4}$. It was noteworthy that the difference in the two emission wavelengths was rather large (emission shift: $\Delta \lambda=100 \mathrm{~nm}$ ), which could fully meet the requirements of ratiometric detection and then acquire accurate results. Moreover, with the change of emission intensity ratios, the fluorescent colors of the system changed correspondingly, offering the possibility for visual identification. Herein, we would like to describe the new ratiometric detection system for $\mathrm{N}_{2} \mathrm{H}_{4}$ in detail, featuring advantages such as relative good solubility in aqueous media, easy-to-synthesize, large emission shift, good ratiometric response, as well as the successful application in real water sample and bioimaging in living cells. 


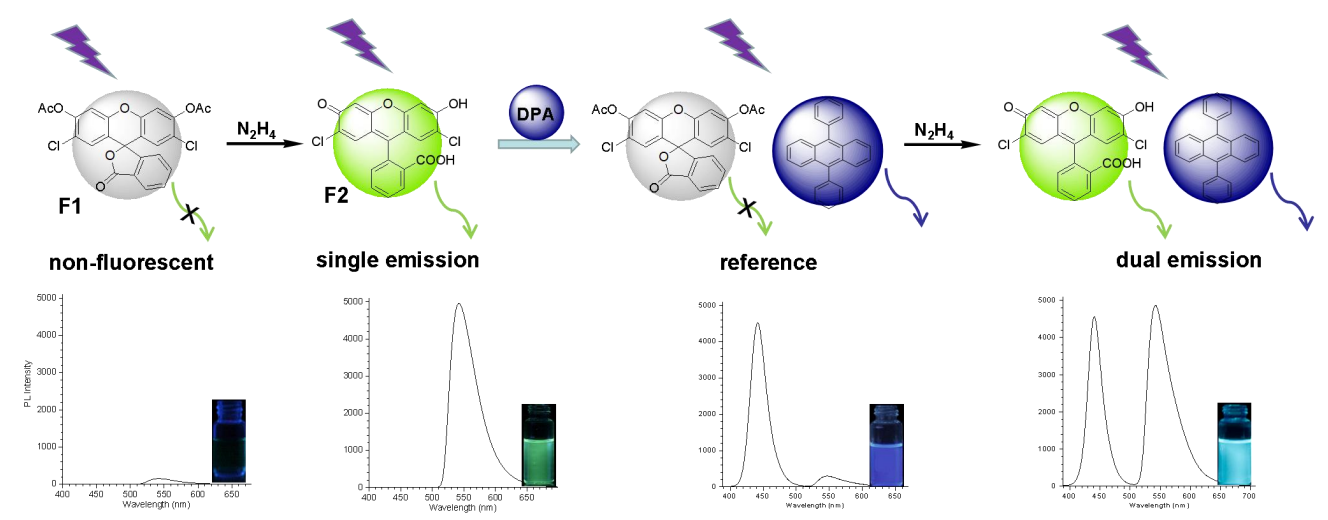

Scheme 1. Schematic illustration of the ratiometric detection system for $\mathrm{N}_{2} \mathrm{H}_{4}$.

\section{Experimental Section}

\subsection{Materials and Instrumentations}

All reagents and solvents were of analytical grade without further purification. 4-(2-Hydroxyethyl)-1-piperazineethanesulfonic acid (HEPES) was purchased from Sigma-Aldrich Chemical Company. The solutions of anions and cations were prepared from their sodium and chloride salts, respectively. Deionized water was used in all experiments.

The ${ }^{1} \mathrm{H}$ and ${ }^{13} \mathrm{C}$ NMR spectra were measured on Bruker500 spectrometer using tetramethylsilane (TMS; $\delta=0 \mathrm{ppm}$ ) as internal standard. The ESI mass spectra were measured on a Finnigan LCQ advantage mass spectrometer. Melting points were measured on a Beijing Taike XT-4 microscopy melting point apparatus, and the thermometer was uncorrected. The $\mathrm{pH}$ values were determined by using a DELTA $320 \mathrm{PH}$ dollar. Photoluminescence spectra were performed on a Hitachi F-7000 fluorescence spectrophotometer.

\subsection{Synthesis of Compound F1}

Compound F1 was synthesized according to the literature method [34]. The resulting solid was collected by filtration and recrystallized in absolute ethanol to give compound F1 as a red solid (59\%). m. p. $165-167^{\circ} \mathrm{C} .{ }^{1} \mathrm{H}$ NMR (500 MHz, $d_{6}$-DMSO) 2.51 (s, $\left.6 \mathrm{H},-\mathrm{CH}_{3}\right), 6.79$ (s, $\left.1 \mathrm{H}, \mathrm{ArH}\right), 7.55-7.57$ (d, $J$ $=10.0 \mathrm{~Hz}, 1 \mathrm{H}, \operatorname{ArH}), 7.66(\mathrm{~s}, 2 \mathrm{H}, \mathrm{ArH}), 7.74(\mathrm{~s}, 1 \mathrm{H}, \operatorname{ArH}), 7.84-7.87(\mathrm{t}, J=7.5 \mathrm{~Hz}, 1 \mathrm{H}, \operatorname{ArH})$, 7.94-7.98 (t, $J=10.0 \mathrm{~Hz}, 1 \mathrm{H}, \mathrm{ArH}), 8.36-8.37(\mathrm{~d}, J=5.0 \mathrm{~Hz}, 1 \mathrm{H}, \mathrm{ArH}) .{ }^{13} \mathrm{C}$ NMR $(125 \mathrm{MHz}$, $d_{6}$-DMSO) 20.3, 112.4, 120.5, 123.2, 127.2, 129.8, 130.1, 131.2, 132.8, 145.3, 145.9, 148.8, 168.1, 168.9 ppm. MS (ESI), m/z [M+H]+: 485.2, calcd, 485.0.

\subsection{General Fluorescence Spectra Measurements of F1 and F1-DPA}

A solution of $\mathbf{F 1}\left(1 \times 10^{-5} \mathrm{~mol} / \mathrm{L}\right)$ was prepared in HEPES : DMSO = 9:1 $(\mathrm{v} / \mathrm{v}, 10 \mathrm{mM}, \mathrm{pH}=7.4)$.

Commercially available hydrazine hydrate was titrated according to the literature [35] and its mass fraction was calculated to be $76 \%$. Then, $1.25 \mathrm{~mL}$ of the above hydrazine solution was placed into a 10 $\mathrm{mL}$ volumetric flask with deionized water to obtain the stock solution of $\mathrm{N}_{2} \mathrm{H}_{4}$ with the concentration of 
$3.0 \times 10^{-3} \mathrm{~mol} / \mathrm{L}$.

The solution of other competitive species $\left(1 \times 10^{-1} \mathrm{~mol} / \mathrm{L}\right)$ were prepared in deionized water. The solution of F1 was placed in a quartz cell (10.0 mm width) and the fluorescence spectrum was recorded. $\mathrm{N}_{2} \mathrm{H}_{4}$, anion or amine was introduced in portions and fluorescence intensity changes were recorded at room temperature each time (excitation wavelength $=390 \mathrm{~nm}$ ).

$1 \mathrm{mmol} \mathbf{F 1}$ and $1.5 \mathrm{mmol}$ DPA were added to $2 \mathrm{~mL}$ of DMSO, then the mixture was diluted with $8 \mathrm{~mL}$ HEPES to obtain the stock solution of F1-DPA with their concentration of 0.1 and $0.15 \mathrm{~mol} / \mathrm{L}$, respectively. During the titration experiment, the above stock solution was diluted to $1 \times 10^{-5} \mathrm{~mol} / \mathrm{L}$. The solution of F1-DPA was placed in a quartz cell (10.0 mm width) and the fluorescence spectrum was recorded. $\mathrm{N}_{2} \mathrm{H}_{4}$, anion or amine was introduced in portions and fluorescence intensity changes were recorded at room temperature each time (excitation wavelength $=390 \mathrm{~nm})$.

\subsection{Real Detection in Water Sample}

For the preparation of water samples, $10 \mathrm{~mL}$ of fresh water sample from the Hanjiang River water was collected in a sample tube. The above sample was filtered three times using a $0.22 \mu \mathrm{m}$ membrane to remove any solid suspensions. The obtained filtration samples were spiked with different concentrations of $\mathrm{N}_{2} \mathrm{H}_{4}$ and their emission spectra were measured as above. The tap water sample was spiked with different concentrations of $\mathrm{N}_{2} \mathrm{H}_{4}$ directly and the emission spectra were measured.

\subsection{Fluorescence Imaging}

HeLa cells were seeded to the 24 -well plates, and then the cells with an initial density of $5 \times 10^{4}$ cells well ${ }^{-1}$ were routinely maintained at $37^{\circ} \mathrm{C}$ in a humidified $5 \% \mathrm{CO}_{2}$ atmosphere using DMEM (Dulbecco's modified eagle's medium) supplemented with $10 \%$ fetal bovine serum and $1 \%$ penicillin-streptomycin for $24 \mathrm{~h}$.

Fluorescence cell imaging was performed with an OLYMPUS IX73 scanning microscopy with a $40 \times$ objective lens. Fluorescence images of HeLa cells were monitored at 400-410 nm and 460-490 nm (the excitation wavelength) for blue and green channels, respectively. The data were analyzed using software package provided by OLYMPUS instruments.

\section{Results and Discussion}

\subsection{Sensing Properties of F1}

Firstly, we added hydrazine into the diluted solution of F1 and investigated its response towards $\mathrm{N}_{2} \mathrm{H}_{4}$ in detail. For the purpose of physiological application, 10 mM HEPES with 10\% DMSO was chosen as the test media to investigate the sensing behavior of F1. Considering that the reaction rate might affect the experimental results, the influence of the reaction time on the probing results was also investigated, and the obtained results were demonstrated in supplementary data Figure S1. With the addtion of different concentrations of $\mathrm{N}_{2} \mathrm{H}_{4}\left(5,10\right.$ and $\left.15 \times 10^{-6} \mathrm{~mol} / \mathrm{L}\right)$, a plateau of intensity at $540 \mathrm{~nm}$ could be achieved after 
10 minutes and the changes became slight from 10 to 15 minutes. Thus, in the titration experiment, we measured the optical intensity changes of the F1 solutions 10 minutes later after all the species were added.

As shown in Figure 1, the emission spectra displayed apparent enhancement with the increasing concentration of $\mathrm{N}_{2} \mathrm{H}_{4}$. It was noteworthy that in the presence of as low as $0.3 \mu \mathrm{M}$ of $\mathrm{N}_{2} \mathrm{H}_{4}$, the emission spectra of sensing system displayed obvious changes, indicating that fluorescent probe $\mathbf{F} 1$ had rather high sensitivity towards $\mathrm{N}_{2} \mathrm{H}_{4}$. When $10 \mu \mathrm{M}$ of $\mathrm{N}_{2} \mathrm{H}_{4}$ was added, the emission intensity at $540 \mathrm{~nm}$ reached the maxmum with about 100-fold enhancement $\left(\mathrm{I} / \mathrm{I}_{0}-1\right)$. Furthermore, this fluorescence difference of the solution of $\mathbf{F 1}$ before and after the addition of $\mathrm{N}_{2} \mathrm{H}_{4}$ could be easily distinguished by the naked eyes. As displayed in the inset of Figure 1, under a normal UV lamp, the solution changed from nearly nonfluorescence to strongly green fluorescence with the quantum yield increasing from 0.12 to 0.43 . Well behaved fluorescence probes should not only be good at qualitative analysis, but also measure the analytes quantitatively. Thus, the linearity of F1 was investigated via the fluorescence titration. As shown in the inset of Figure 1, with the amount of hydrazine solution gradually increasing, the fluorescent intensity rose step by step. According to the linear curve, $R^{2}$ of probe $\mathbf{F} 1$ was caculated to be 0.9972 , exhibiting good linearity and exact quantitative detection towards the concentration of hydrazine. The detection limit of probe $\mathbf{F 1}$ was evaluated based on the above fluorescence titration and then calculated with the following equation: detection limit $=3 \sigma / k$ (where $\sigma$ is the standard deviation of blank measurement acquired by ten times measurement of emission spectrum of F1; $k$ is the slope from the inset plot in Figure 1). Accordingly, the detection limit of probe F1 was calculated to be as low as $90 \mathrm{nmol} / \mathrm{L}$.

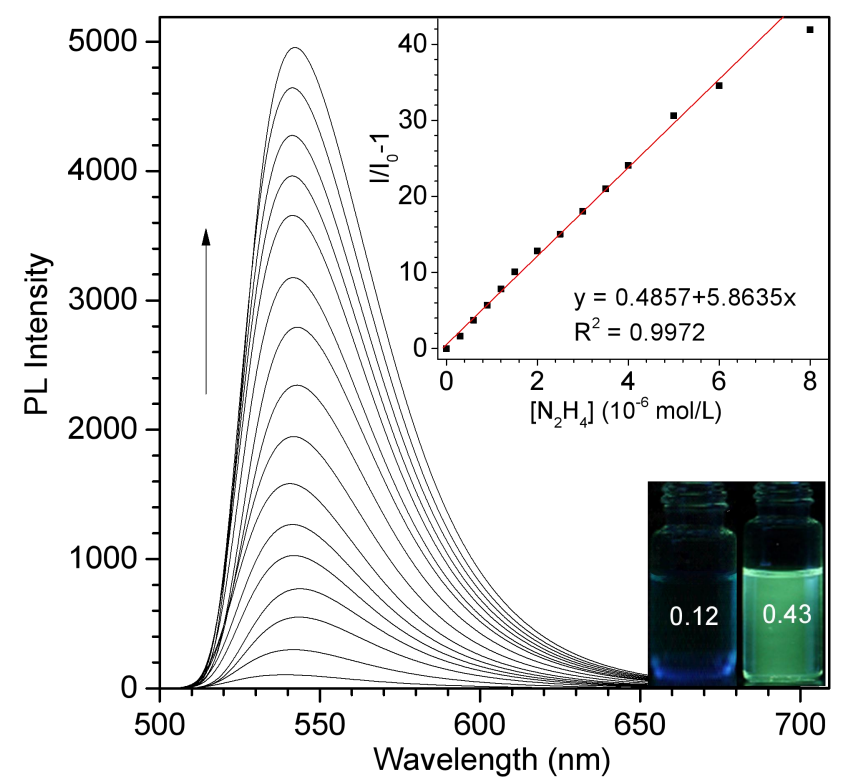

Figure 1. Fluorescent emission spectra of $\mathbf{F 1}\left(10 \mu \mathrm{M}\right.$, in $\left.\mathrm{H}_{2} \mathrm{O} / \mathrm{DMSO}=9 / 1, \mathrm{v} / \mathrm{v}\right)$ in the presence of increasing concentration of $\mathrm{N}_{2} \mathrm{H}_{4}$ (from bottom to top: $0.0 、 0.3 、 0.6 、 0.9 、 1.2 、 1.5 、 2.0 、 2.5 、 3.0$ 、 3.5 $、 4.0 、 4.5 、 5.0 、 6.0 、 8.0$ and $10.0 \mu \mathrm{mol} / \mathrm{L}$ ), excited at $390 \mathrm{~nm}$. Inset: Plot of fluorescent intensity at $540 \mathrm{~nm}$ of $\mathbf{F 1}$ as a function of the concentration of $\mathrm{N}_{2} \mathrm{H}_{4}$, and fluorescent photograph of $\mathbf{F} 1$ before and 
after the addition of $\mathrm{N}_{2} \mathrm{H}_{4}$.

To evaluate the specificity of $\mathbf{F} 1$ toward $\mathrm{N}_{2} \mathrm{H}_{4}$, the influence of representative cations (including $\mathrm{Mg}^{2+}, \mathrm{Zn}^{2+}, \mathrm{Ni}^{2+}, \mathrm{Ba}^{2+}, \mathrm{Al}^{3+}, \mathrm{Cd}^{2+}$ ), anions (including $\mathrm{SO}_{3}^{2-}, \mathrm{S}_{2} \mathrm{O}_{3}{ }^{2-}, \mathrm{ClO}_{3}^{-}, \mathrm{F}^{-}, \mathrm{Br}^{-}, \mathrm{I}^{-}, \mathrm{AcO}^{-}, \mathrm{HCO}_{3}^{-}$), and neutral nitrogen-containing compounds (including urea, n-butylamine, ethylenediamine, diisobutylamine) were investigated under the same condition. As shown in Figure S2, only in the presence of $\mathrm{N}_{2} \mathrm{H}_{4}$, the strong emission at $540 \mathrm{~nm}$ could be observed. Furthermore, we measured the response of $\mathbf{F} 1$ to $\mathrm{N}_{2} \mathrm{H}_{4}$ in the presence of other competitive species. As shown in the inset of Figure $\mathrm{S} 2$, the presence of all other interferents did not cause any appreciable changes to the fluorescence spectra, indicating that probe $\mathbf{F} 1$ had selective response toward $\mathrm{N}_{2} \mathrm{H}_{4}$.

\subsection{Sensing Properties of F1-DPA System}

The above experimental results demonstrated that compound $\mathbf{F} 1$ could act as a single intensity-based fluorescent probe for $\mathrm{N}_{2} \mathrm{H}_{4}$ detection. Then, DPA was utilized to serve as an internal reference to gain ideal ratiometric probe and the sensing behavior of the F1-DPA system to $\mathrm{N}_{2} \mathrm{H}_{4}$ has been explored carefully. In the absence of $\mathrm{N}_{2} \mathrm{H}_{4}$, two well-resolved emission peaks centered at 440 and $540 \mathrm{~nm}$ were observed, which can be ascribed to the emission of DPA and F1, respectively. As presented in Figure 2, when the concentration of $\mathrm{N}_{2} \mathrm{H}_{4}$ increased from 0 to $8.0 \mu \mathrm{M}$, the emission intensity at $540 \mathrm{~nm}$ increased gradually, while the intensity at $440 \mathrm{~nm}$ of compound DPA almost kept constant. Actually, even at the concentration of $\mathrm{N}_{2} \mathrm{H}_{4}$ as low as $0.3 \mu \mathrm{M}$, apparent spectra changes could be observed with respect to the blank solution. It was noteworthy that the difference in the two emission wavelengths was large enough (emission shift: $\Delta \lambda=100 \mathrm{~nm}$ ) to accurately measure the intensities of two emission peaks and then obtain a huge ratiometric value. Actually, in the presence of $8.0 \mu \mathrm{M}$ of $\mathrm{N}_{2} \mathrm{H}_{4}$, a ca. 270 -fold enhancement in the ratiometric value of $I_{540} / I_{440}$ was achieved with respect to the $\mathrm{N}_{2} \mathrm{H}_{4}$-free solution (from 0.005 to 1.34 ). Correspondingly, the fluorescence color changed from violet to cyan (Scheme 1, inset), which could be easily distinguished by the naked eyes under the aid of a normal UV lamp.

To see the sensing process more visually, we compared the intensities at different wavelengths of 540 and $440 \mathrm{~nm}$. As shown from Figure 3, there was a good linear relationship between the ratiometric value of $I_{540} / I_{440}$ and the concentration of $\mathrm{N}_{2} \mathrm{H}_{4}$, which would be beneficial to the quantitative determination of $\mathrm{N}_{2} \mathrm{H}_{4}$ concentrations. Thus, the F1-DPA sensing system could efficiently detect the F1-DPA system with ratiometric response, as expected. 


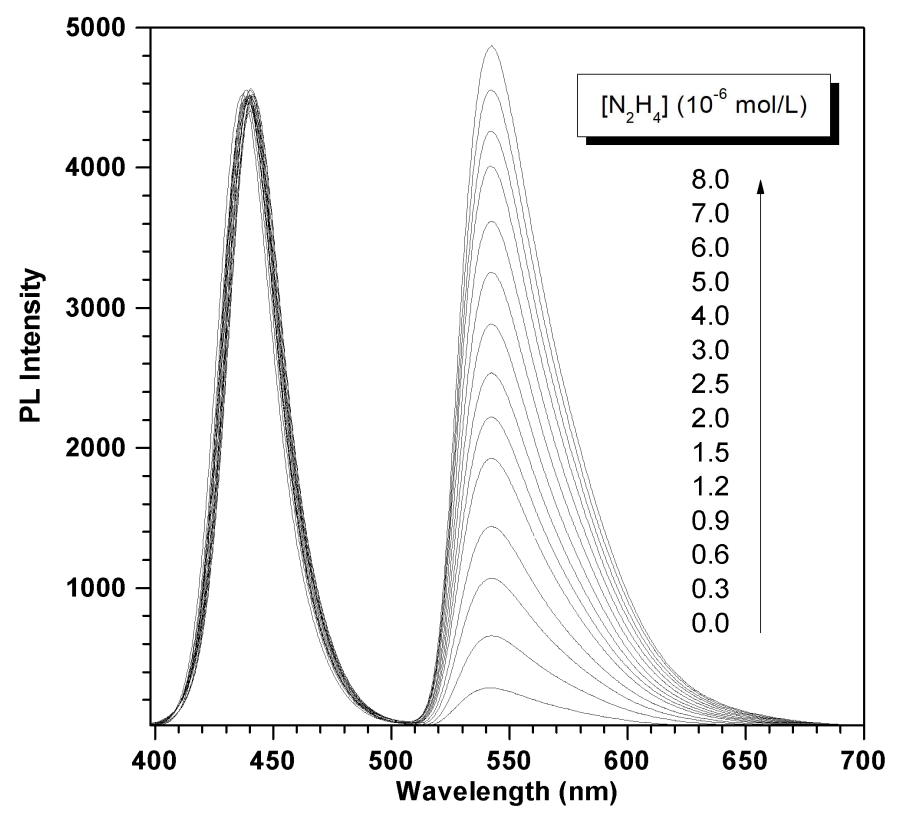

Figure 2. Fluorescent emission spectra of F1-DPA system in the presence of increasing concentration of $\mathrm{N}_{2} \mathrm{H}_{4}$, excited at $390 \mathrm{~nm}$.

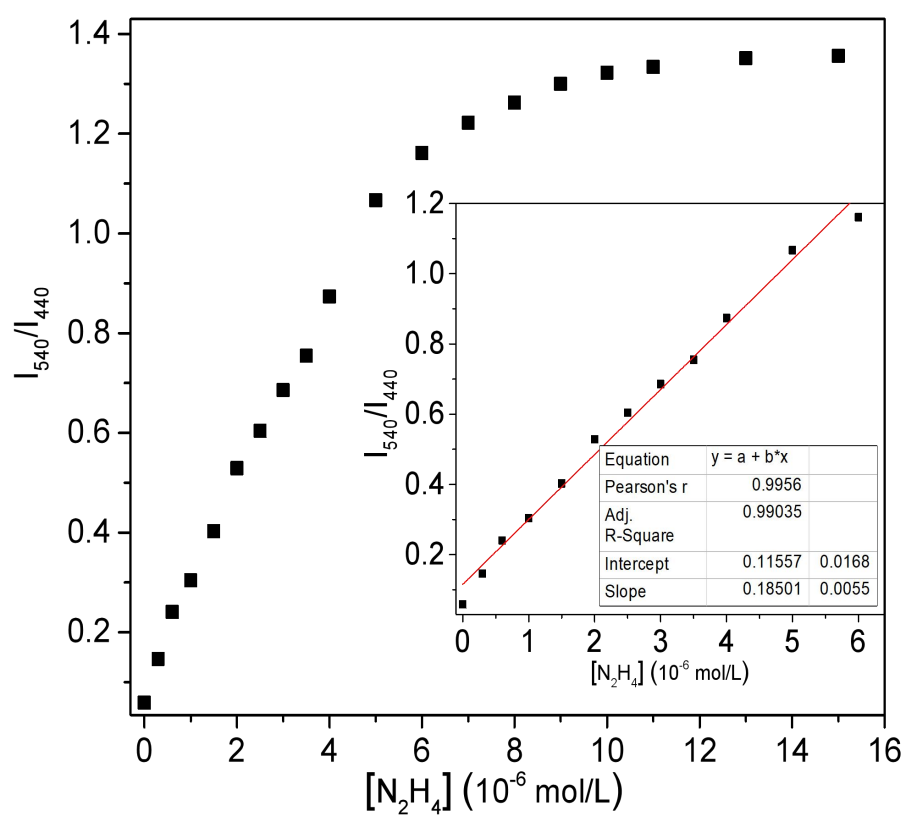

Figure 3. Plot of fluorescent intensity at $540 / 440 \mathrm{~nm}$ of F1-DPA system as a function of the concentration of $\mathrm{N}_{2} \mathrm{H}_{4}$.

Also, the influence of other competitive species was investigated to evaluate the specific nature of F1-DPA system towards $\mathrm{N}_{2} \mathrm{H}_{4}$. As shown in Figure S3, these competitive species did not lead to any significant fluorescence changes, and only $\mathrm{N}_{2} \mathrm{H}_{4}$ elicited dramatic fluorescence spectra response. The above results indicated that the F1-DPA system could act as a new method for detection of $\mathrm{N}_{2} \mathrm{H}_{4}$ with good selectivity and strong anti-interference ability. 


\subsection{Proposed Sensing Mechanism}

In order to understand the hydrazine sensing mechanism, probe F1 reacted fully with excess $\mathrm{N}_{2} \mathrm{H}_{4}$ and the isolated product was characterized by ${ }^{1} \mathrm{H}$ NMR spectra spectrometry. As shown in Figure 4, after the addition of hydrazine, the methyl signal at $2.51 \mathrm{ppm}$ disappeared due to the hydrazinolysis of the acetyl group. Meanwhile, the signal at 4.53 and $10.37 \mathrm{ppm}$ appeared due to the formation of phenolic hydroxyl group and carboxyl group, respectively. To further confirm this transformation, the reaction mixture of $\mathbf{F} 1$ with $\mathrm{N}_{2} \mathrm{H}_{4}$ was characterized by ESI-MS spectrometry. The ESI-MS spectrum of $\mathrm{N}_{2} \mathrm{H}_{4}$ in supplementary data Figure S4 revealed a main peak at 485.2 before the addition of $\mathrm{N}_{2} \mathrm{H}_{4}$, corresponding to the species $[\mathbf{F 1}+\mathrm{H}]^{+}\left(\mathrm{m} / z_{\text {caled }}=485.0\right)$. After the addition of excess $\mathrm{N}_{2} \mathrm{H}_{4}$ and incubation for 10 minutes, a major peak at about 399.4 appeared coinciding exactly with that for the adduct species $\left[\mathbf{F} 2-\mathrm{H}^{-}\left(\mathrm{m} / \mathrm{z}_{\text {caled }}=398.9\right)\right.$. Therefore, all these data indicated that the reaction most likely followed the proposed mechanism as shown in Figure 4: upon the addtion of $\mathrm{N}_{2} \mathrm{H}_{4}$, the $\mathrm{N}_{2} \mathrm{H}_{4}$-promoted hydrazinolysis reaction really occurred, which triggered the cleavage of the $\mathrm{C}-\mathrm{O}$ bond in compound $\mathbf{F} 1$. And then, the released phenolic hydroxyl moiety could easily undergo structural transformation, resulting in the photoswitch of the non-fluorescent deconjugated form to the strongly fluorescent conjugated one (F2).
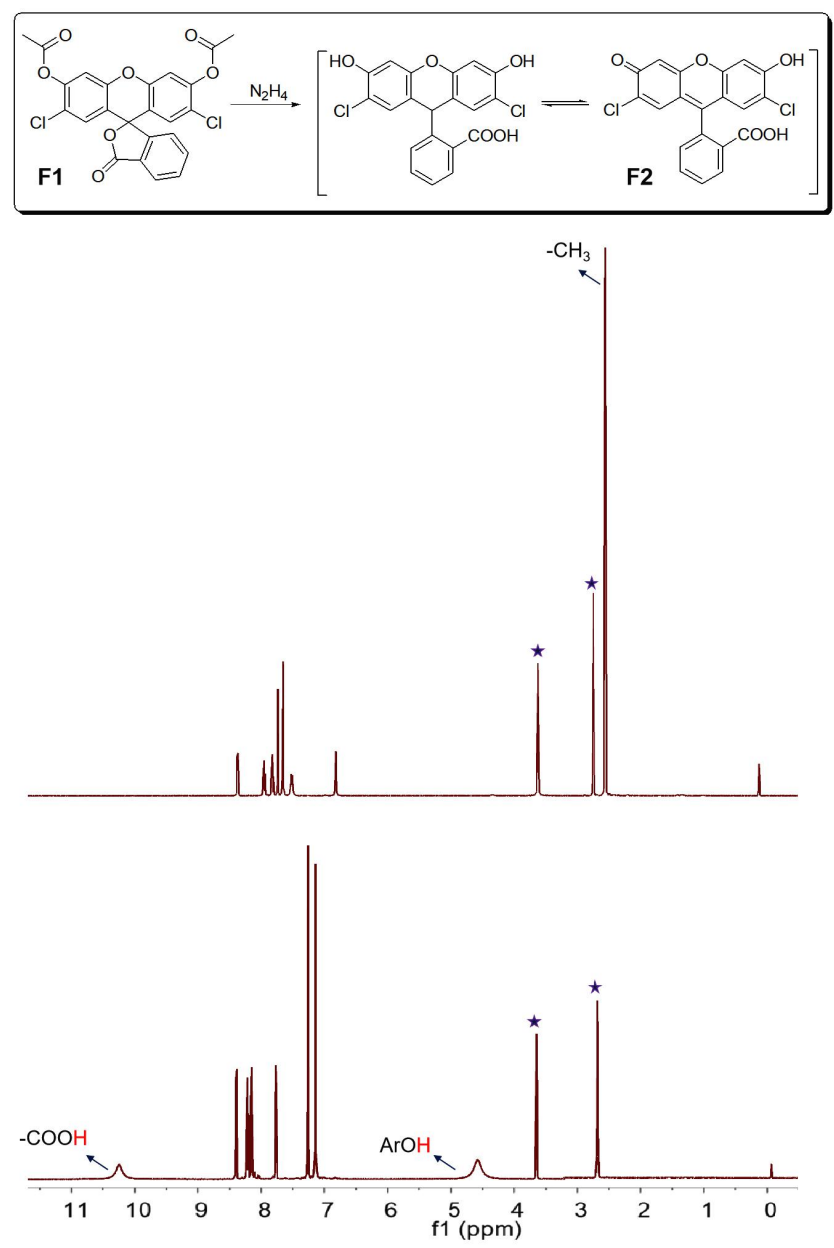

Figure 4. ${ }^{1} \mathrm{H}$ NMR spectra of compound $\mathbf{F 1}$ (the top) and its hydrazine adduct (the bottom) in $d_{6}$-DMSO (the signal of the solvent was marked with an asterisk). 


\subsection{Application in Water Sample}

In order to explore the practical application in water sample detection, F1-DPA probe system was used to detect hydrazine in tap water and Hanjiang River water. We applied a spiked method to estimate the concentrations of $\mathrm{N}_{2} \mathrm{H}_{4}$ in different samples and each measurement was done in quintuplicate. The standard curve in Figure 3 was used for measurement and the analytical results was shown in Table 1. It was found that the obtained recovery rate were satisfactory for quantitative assays. The above results confirmed the feasibility and reliability of the proposed probe for hydrazine detection in real water samples.

Table 1 The determination of hydrazine in water samples (a: the results were shown as the average of five measurements)

\begin{tabular}{|c|c|c|c|c|}
\hline Sample & & Added & ${ }^{a}$ Found & Recovery \\
\hline \multirow{5}{*}{\multicolumn{2}{|c|}{ Tap water }} & 0.60 & 0.63 & 105 \\
\hline & & 1.50 & 1.39 & 92.6 \\
\hline & & 2.40 & 2.33 & 97 \\
\hline & & 3.00 & 3.07 & 102 \\
\hline & & 3.60 & 3.41 & 94.7 \\
\hline \multirow[t]{5}{*}{ Hanjiang } & River & 0.60 & 0.57 & 95 \\
\hline & & 1.50 & 1.41 & 94 \\
\hline & & 2.40 & 2.35 & 97.9 \\
\hline & & 3.00 & 2.95 & 98.3 \\
\hline & & 3.60 & 3.67 & 101.9 \\
\hline
\end{tabular}

\subsection{Cell Imaging}

The application of F1-DPA system to track intracellular $\mathrm{N}_{2} \mathrm{H}_{4}$ level was also investigated. Before the fluorescent imaging experiment, Hela cells were stained with DPA $(30 \mu \mathrm{M})$ and F1 $(20 \mu \mathrm{M})$ for 20 min followed by subsequent treated with $50 \mu \mathrm{M} \mathrm{N} \mathrm{N}_{2} \mathrm{H}_{4}$ for another $20 \mathrm{~min}$, and then washed with phosphate-buffered saline (PBS, $10 \mathrm{mM}, \mathrm{pH}$ 7.12) for three times. In the control experiment, HeLa cells were treated only with F1-DPA for $20 \mathrm{~min}$ and washed three times with PBS. By virtue of a scanning microscopy, we could observe that the mean intensity of the emission collected at the green channel increased after the addition of $\mathrm{N}_{2} \mathrm{H}_{4}$ as shown in Figure 5. In contrast, the green fluorescence was little observable in the cells prior to the $\mathrm{N}_{2} \mathrm{H}_{4}$ treatment (Figure 5b). Accordingly, the fluorescence images of F1-DPA system before and after the addition of $\mathrm{N}_{2} \mathrm{H}_{4}$ was monitored and the mean blue to green intensities $(\mathrm{FB} / \mathrm{FG})$ were found to be 7.53 and 0.92 ratio using software package provided by OLYMPUS instruments, respectively. The bright-field images (Figure $5 \mathrm{c}$ and $\mathrm{f}$ ) confirmed that the 
cells were viable throughout the imaging experiments. The imaging experiment results were consistent with the observations in titration experiments, and demonstrated this probe system could readily sense $\mathrm{N}_{2} \mathrm{H}_{4}$ in cells with ratiometric fluorescent methods.
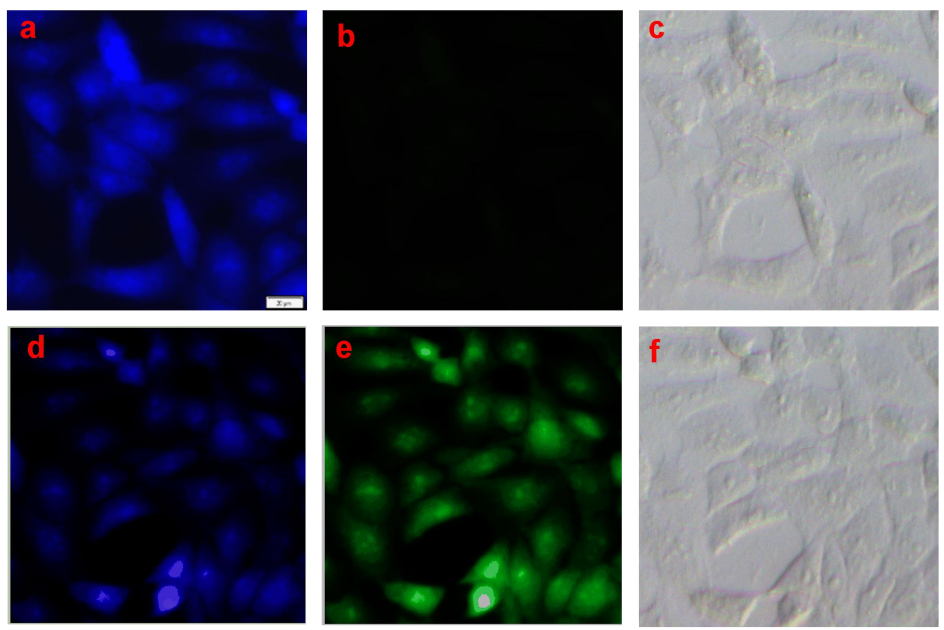

Figure 5. The top: image of HeLa cells incubated with F1-DPA for $20 \mathrm{~min}$. a: fluorescence at the blue emission channel; b: fluorescence at the green emission channel; c: bright field images. The bottom: image of HeLa cells pre-treated with F1-DPA for $20 \mathrm{~min}$ and then incubated with $\mathbf{N}_{\mathbf{2}} \mathbf{H}_{\mathbf{4}}(50 \mu \mathrm{M})$ for 20 min; d: fluorescence at the blue emission channel; e: fluorescence at the green emission channel; f: bright field images. Scale bar: $20 \mu \mathrm{m}$.

\section{Conclusion}

In summary, we presented a ratiometric method for $\mathrm{N}_{2} \mathrm{H}_{4}$ detection through simple combination of DPA and $\mathrm{N}_{2} \mathrm{H}_{4}$-specifity probe F1. The addition of $\mathrm{N}_{2} \mathrm{H}_{4}$ induced a significantly enhanced emission intensity of probe F1 while the emission intensity of DPA almost kept constant, inducing fluorescence intensity ratio response toward $\mathrm{N}_{2} \mathrm{H}_{4}$. Taking advantages of its unique alkalinity, the present F1-DPA sensing system showed excellent selectivity and could successfully identify $\mathrm{N}_{2} \mathrm{H}_{4}$ from other competing species. Furthermore, the tunable fluorescent colors from violet to cyan enable this method to act as a sensitive colorimetric luminescent probe to the $\mathrm{N}_{2} \mathrm{H}_{4}$ concentration distribution. This facile and reliable method could become one of the emerging strategies in analytical chemistry and it was believed that more excellent intensity-based receptors could be utilized as optimal ratiometric ones by virtue of the introduction of proper internal reference.

\section{Author Declarations}

\section{Funding}

This work was financially supported by the National Key Research and Development Plan (2019YFE0107200) and the Xiangyang Science and Technology Project (No. 2020YL03).

\section{Conflicts of interest}


There are no conflicts to declare.

\section{Ethics approval}

For this type of study, the ethical approval was not required, because this study does not involve animal manipulation.

\section{Consent to participate}

All authors gave their consent to participate in the research.

\section{Consent for publication}

All authors gave their consent to participate in the publication of the research.

\section{Availability of data and material}

Not applicable.

\section{Code availability}

Not applicable.

\section{Authors' contributions}

XC: supervision, investigation designed and directed the study, planned and carried out the experiments, wrote the manuscript. MG: the fluorescence spectrum test and analysis. Dr. SL: contributed to the design and synthesis of the organic compounds. Dr. SW: contributed to the characterization of the target molecular and interpretation of the NMR spectra. Dr. WL: contributed to the practical sample detection and cell imaging experiments. All authors read and approved the final manuscript.

\section{References}

1. Yang H, Li M, Zhang Y, Ruan S, Yin J, Song J, Yang Y, Wang Z, Wang S. A smart nopinone-based fluorescent probe for colorimetric and fluorogenic detection of hydrazine in water and plants with high sensitivity and selectivity. (2020) J. Lumin. 226: 117436

2. Yang Y, Liu X, Yan D, Deng P, Guo Z, Zhan H. Europium ion post-functionalized zirconium metal-organic frameworks as luminescent probes for effectively sensing hydrazine hydrate. (2018) RSC Adv. 8: 17471

3. Zhang Y, Huang Y, Yue Y, Chao J, Huo F, Yin C. A compact fluorescent probe based on o-phthalaldehyde for ultrasensitive detection of hydrazine in gas and solution phases. (2018) Sens. Actuators B Chem. 273: 944

4. Li M, He J, Wang Z, Jiang Q, Yang H, Song J, Yang Y, Xu X, Wang S. Novel nopinone-based turn-on fluorescent probe for hydrazine in living cells with high selectivity. (2019) Ind. Eng. Chem. Res. 58: 22754

5. Zhang R, Zhang CJ, Song Z, Liang J, Kwok RTK, Tang BZ, Liu B. AIEgens for real-time naked-eye sensing of hydrazine in solution and on a paper substrate: structure-dependent signal output and selectivity. (2016) J. Mater. Chem. C 4: 2834

6. Liu C, Wang F, Xiao T, Chi B, Wu Y, Zhu D, Chen X. The ESIPT fluorescent probes for $\mathrm{N}_{2} \mathrm{H}_{4}$ 
based on benzothiazol and their applications for gas sensing and bioimaging. (2018) Sens. Actuators B Chem. 256: 55

7. Zhai Q, Feng W, Feng G. Rapid detection of hydrazine in almost wholly water s olution and in living cells with a new colorimetric and fluorescent turn-on probe. (2016) Anal. Methods 8: 5832

8. Xia X, Zeng F, Zhang P, Lu J, Huang Y, Wu S. An ICT-based ratiometric fluorescent probe for hydrazine detection and its application in living cells and in vivo, Sens. Actuators B Chem. (2016) 227: 411

9. Lee MH, Yoon B, Kim JS, Sessler JL. Naphthalimide trifluoroacetyl acetonate: a hydrazine-selective chemodosimetric sensor. (2013) Chem. Sci. 4: 4121

10. Wu G, Tang X, Ji W, Lai KW, Tong Q. A turn-on fluorescent probe based on coumarin-anhydride for highly sensitive detection of hydrazine in the aqueous solution and gas states. (2017) Methods Appl. Fluoresc. 5: 015001

11. Ma J, Fan J, Li H, Yao Q, Xia J, Wang J, Peng X. Probing hydrazine with a nearinfrared fluorescent chemodosimeter. (2017) Dye. Pigment. 138: 39

12. Ragnarsson U. Synthetic methodology for alkyl substituted hydrazines. (2001) Chem. Soc. Rev. 30: 205

13. Vieira IC, Lupetti KO, Fatibello-Filho O. Sweet potato tissue as a biocatalyst in a paraffifin/graphite biosensor for hydrazine determination in boiler feed water. (2002) Anal. Lett. 35: 2221

14. Kroschwitz JI, Seidel A. Hydrazine and Its Derivatives in Kirk-Othmer Encyclopedia of Chemical Technology. (2005) Wiley, New York, 13: 562

15. Niemeier JK, Kjell DP. Hydrazine and aqueous hydrazine solutions: evaluating safety in chemical processes. (2013) Org. Process Res. Dev. 17: 1580

16. Reilly CA, Aust SD. Peroxidase substrates stimulate the oxidation of hydralazine to metabolites which cause single-strand breaks in DNA. (1997) Chem. Res. Toxicol. 10: 328

17. Elder DP, Snodin D. Teasdale A. Control and analysis of hydrazine, hydrazides and hydrazones-genotoxic impurities in active pharmaceutical ingredients (APIs) and drug products. (2011) J. Pharm. Biomed. Anal. 54: 900

18. Xu WZ, Li X, Han MN, Zhou TT, Yang YT, Li W. A fluorescent probe for hydrazine based on synergistic effect and its utilization in cell imaging. (2020) Chin. J. Org. Chem. 40: 181

19. Sun Y, Zhao D, Fan SW, Duan L. A 4-hydroxynaphthalimide-derived ratiometric fluorescent probe for hydrazine and its in vivo applications. (2015) Sens. Actuators B Chem. 208: 512

20. Ran YZ, Xu HR, Li K, Xu KK, Yang J, Yu XQ. Development of a mitochondria targeted fluorescent probe for hydrazine monitoring in living cells. (2016) RSC Adv. 6: 111016

21. Ma JH, Fan JL, Li, HD, Yao QC, Xia J, Wang JY, Peng XJ. Probing hydrazine with a near-infrared fluorescent chemodosimeter. (2017) Dyes Pigm. 138: 39 
22. Tang W, Xiang Y, Tong A. Salicylaldehyde azines as fluorophores of aggregation-induced emission enhancement characteristics. (2009) J. Org. Chem. 74: 2163

23. Cui L, Peng ZX, Ji CF, Huang JH, Huang DT, Ma J, Zhang SP, Qian XH, Xu YF. Hydrazine detection in the gas state and aqueous solution based on the Gabriel mechanism and its imaging in living cells. (2014) Chem. Commun. 50: 1485

24. Fan JL, Sun W, Hu MM, Cao JF, Cheng GH, Dong HJ, Song KD, Liu YC, Sun SG, Peng XJ. An ICT-based ratiometric probe for hydrazine and its application in live cells. (2012) Chem. Commun. 48: 8117

25. ImamReja S, Gupta N, Bhalla V, Kaur D, Arora S, Kumar M. A charge transfer based ratiometric fluorescent probe for detection of hydrazine in aqueous medium and living cells. (2016) Sens. Actuators B Chem. 222: 923

26. Chen SH, Jiang K, Xiao Y, Cao XY, Arulkumar M, Wang ZY. Recent endeavors on design, synthesis, fluorescence mechanisms and applications of benzazole-based molecular probes toward miscellaneous species. (2020) Dyes Pigments 175: 108157

27. Liu X, Liu J, Zhou H, Yan ML, Liu CJ, Guo XD, Xie J, Li SY, Yang GQ. Ratiometric dual fluorescence tridurylboron thermometers with tunable measurement ranges and colors. (2020) Talanta 210: 120630

28. Ge LH, Liu ZC, Tian Y. A novel two-photon ratiometric fluorescent probe for imaging and sensing of BACE1 in different regions of AD mouse brain. (2020) Chem. Sci. 11: 2215

29. Wu SY, Zhu MC, Zhang Y, Kosinova M, Fedin VP, Gao EJ. A Water-Stable Lanthanide Coordination Polymer as Multicenter Platform for Ratiometric Luminescent Sensing Antibiotics. (2020) Chem. Eur. J. 26: 3137

30. He L, Liu XJ, Zhang Y, Yang L, Fang Q, Geng YN, Chen WQ, Song XZ. A mitochondria-targeting ratiometric fluorescent probe for imaging hydrogen peroxide with long-wavelength emission and large Stokes shift. (2018) Sens. Actuators B Chem. 276: 247

31. Li MX, Feng WY, Zhang HY, Feng GQ. An aza-coumarin-hemicyanine based near-infrared fluorescent probe for rapid, colorimetric and ratiometric detection of bisulfite in food and living cells. (2017) Sens. Actuators B Chem. 243: 51

32. Feng, WY, Hong JX, Feng WY, Feng GQ. Colorimetric and ratiometric fluorescent detection of carbon monoxide in air, aqueous solution, and living cells by a naphthalimide-based probe. (2017) Sens. Actuators B Chem. 251: 389

33. Feng WY, Bai LY, Jia, SW, Feng, GQ. A novel phthalimide-rhodol-based ESIPT-FRET system for rapid colorimetric and ratiometric fluorescent detection of palladium (2018) Sens. Actuators B Chem. 260: 554

34. Yang ZQ, Liu XK, Jiang LN, Wang M. Design, Synthesis and Application of Fluorescence Resonance Energy Transfer-Based Ratiometric Hydrazine Fluorescent Probe (2019) Chin. J. Org. Chem. 39: 1483 
35. Song YC, Zong LY, Zhang LY, Li Z. To form AIE product with the target analyte: a new strategy for excellent fluorescent probes, and convenient detection of hydrazine in seconds with test strips. (2017) Sci. China. Chem. 12: 1596 